Article

\title{
Morphology and Material Composition of the Mouthparts of Stromatium unicolor Olivier 1795 (Coleoptera: Cerambycidae) for Bionic Application
}

\author{
Roberto D. Martínez *(D), Luis-Alfonso Basterra ${ }^{(D)}$, Luis Acuña ${ }^{\mathbb{D}}$ and José-Antonio Balmori ${ }^{(\mathbb{D}}$ \\ Timber Structures and Wood Technology Research Group, UVa, 47014 Valladolid, Spain; \\ basterra@arq.uva.es (L.-A.B.); maderas@iaf.uva.es (L.A.); balmori@arq.uva.es (J.-A.B.) \\ * Correspondence: robertomartinez@arq.uva.es
}

Received: 19 April 2020; Accepted: 25 June 2020; Published: 27 June 2020

\begin{abstract}
Research Highlights: The novelty of this study is the deep analysis of the morphologic, geometric and mechanical performance of longhorn beetle larvae mouthparts. Furthermore, a metal nano identification of jaw reinforced parts was made. Background and Objectives: Analysis of insect mechanical properties has shown an important application in the develop of bionic technologies such as new materials, industrial machines and structural concepts. This study aims to determine the mechanical and geometric properties of longhorn beetle (Stromatium unicolor Olivier 1795) larvae mouthparts to improve the development of innovative cutting tools. In addition, this study obtains a nano identification of metals in the cuticle of the mouthparts, which will enable the development of new nontoxic and sustainable preservation agents against xylophagous insects based on nanoparticles. Materials and Methods: five third-larval-stage samples of Stromatium unicolor were used to study its mandible morphologic, geometric and mechanical properties. To this end, mouthparts were analyzed by several microscopic techniques using a scanning electron microscope, a stereomicroscope and an optical microscope. Composition analysis was performed using with two Analytical-Inca $X$-ray detectors, dispersive energy spectroscopy and dispersive wavelength spectroscopy. Results: The main geometric parameters of the insect jaw are the edge angle $\left(\beta=77.3^{\circ}\right)$, maximum path depth of the insect $(120 \mu \mathrm{m})$, length $(800 \mu \mathrm{m})$ and mouthpart movement, which were identified and measured. The chemical analysis results of the jaw tissues shows the presence of zinc and manganese. Conclusions: The geometry and angles of the mouthparts can be applied in the fabrication of bionic self-sharpening cutting tools. Molecular compounds that form the reinforcing elements in the jaws can be used to develop wood preservatives based on nanometals and metal absorption and metabolism inhibitors.
\end{abstract}

Keywords: bionics; mouthparts; microstructure; nanoindentation properties; working efficiency

\section{Introduction}

Bionic science studies nature and natural organisms to understand their geometry and physical, chemical, structural and material properties underlying biologic principles. These bionic concepts are found to transfer biologic solutions to engineering, medicine, smart technology and general science. This knowledge has been well developed as a scientific approach to design new technology and optimize existing ones. Thus, currently, it is possible to find hundreds of examples of bionic influence on our daily lives that involve the transformation of the principles of nature into technology [1-4]. In the last decades, bionic science witnessed a huge increase. The combination of new imaging analysis techniques such as synchrotron-generated X-rays, microtomography, laser scanning microscopy, energy disperse spectroscopy and scanning electron microscopy has enabled further studies of the morphology 
and mechanical properties of live animals, plants and insects. These techniques have resulted in new knowledge about the chemical composition and nanoindentation properties of specific biologic structures. All of these advances have strongly developed the comprehension of bionic materials and structures $[5,6]$.

Insect structure and function investigations have shown promise for use in mechanical, informational and intelligential new bionic devices [7]. Almost 99\% of insects can fly; their aerodynamic behavior and flight skills have been repeatedly applied in mechanical engineering to promote new design concepts for aerodynamic or flight vehicles [8,9]. Other applications of insect bionics have been to develop new composite materials, more rigid and strong materials, materials that save weight $[10,11]$ or to inspire new structure designs [12].

Therefore, the biomechanical and morphology analysis of insect mouthparts can directly contribute to cutting-edge engineering developments. Insects—especially their larvae-can easily cut and eat vegetables and wood of different hardness. This ease of cutting depends on their well-formed, strong and sharply shaped mouthparts, which have evolved to chew different natural materials [13-15]. In all cases, the mouthparts-whose main function is to chew-must be stiffer, harder, stronger and more resistant than the food to prevent breakage, wear or deformation. Similarly, it must have a good cutting tool [16,17]. However, insect mouthparts are not always as simple as most metal-cutting tools. Links have been established between tooth geometry and angle of attack, distance, obliqueness, etc., and the effects of these parameters and the forces required to cut natural materials. Research on the basic structure of insect mouthparts, type of jaw, geometry, hardness and elemental content can help solve problems such as the coating of cutting tools or more efficient cutting designs [18]. Thus, several investigations have analyzed the geometric characteristics and shapes of different insect mouthparts to enhance the performance and design of bionic cutting tools. For example, the insect species Locusta migratoria manilensis [19] and Gryllotalpa orientalis [20] were studied to improve the design of the cutting mechanics of agricultural machines. Cyrtotrachelus sp. inspired the design of bionic blades in the food industry [21].

Another focus of research is the analysis of cuticle nano properties. In 1982, Hillerton et al. studied the Locusta migratory insect to find the hardness of different parts of the mouthparts. This study found that some area of the incisor teeth was much harder than other parts of the mandibular cuticle, including two shear surfaces, which suggests that hard surfaces form cutting edges that bite and due to the way that the jaws move, they are also self-sharpening [22]. Several investigations have analyzed the microstructure and elements that insects incorporate into their cuticles as reinforcement to increase their resistance. Numerous studies have identified the presence, type and location of metals in the cuticles of certain groups of insects [23-25]. These elements are normally zinc, manganese, iron, calcium and chlorine, and they are frequently found in high concentrations in the cuticle of various insect structures. Among other structures, jaws frequently contain significant amounts of these metals [26-28]. The concentrations of metals at the cutting edges can improve the mechanical properties of insect jaws [29]. Currently, this nano-identification is applied in the design of bionic blades [30,31].

However, the most promising application of this nano-identification is the development of nontoxic and sustainable preservation agents to apply durable wood treatments with nanoparticles. Some investigations have studied the application of metal nanoparticles by pressure treatment as an effective antimicrobial and antifungal wood preservation method [32-34]. In addition, this treatment can be effective against different xylophagous insects; nanoparticles of specific metals can chemically interact with the metals in the cuticle to weaken the mouthparts and prevent feeding [35-37].

This study aims to determine the specific material, morphologic and mechanical properties of larval-stage longhorn beetle (Stromatium unicolor Olivier 1795) insect mouthparts. Knowledge of the geometric parameters such as the edge angle, relief angle, detachment angle or type of cut that the jaw makes when eating will improve the technology of current cutting tools. In addition, the nano-identification of metal present in the cuticle of mouthparts may enable us to develop 
new sustainable preservation agents against xylophagous insects based on metallic nanoparticles, metal absorption and metabolism inhibitors.

\section{Materials and Methods}

This study was performed on five larvae (third stage) of Stromatium unicolor (Olivier, 1795), which were collected in the town of Nombela (Toledo, Spain), Figure 1. This species is a longhorn beetle whose larvae feed on holm oak (Quercus ilex L.). Each larva was used to study a specific type of parameter, and it was necessary to perform different histological preparations that destroyed the sample. The trace of the cut in the holm oak wood by the larvae was studied by observing the walls of the pierced galleries.

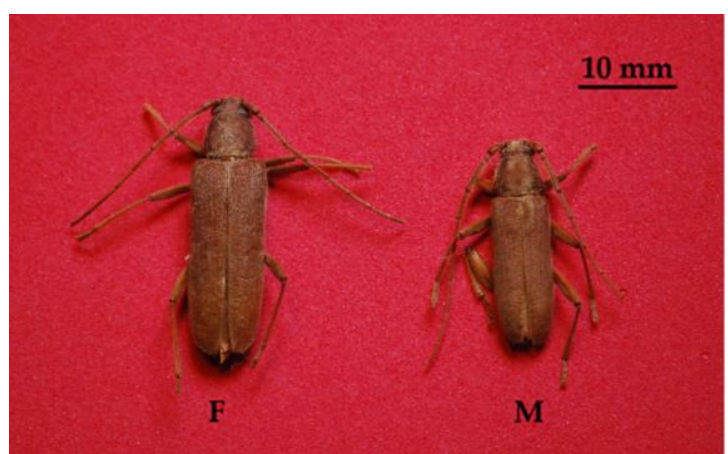

(a)

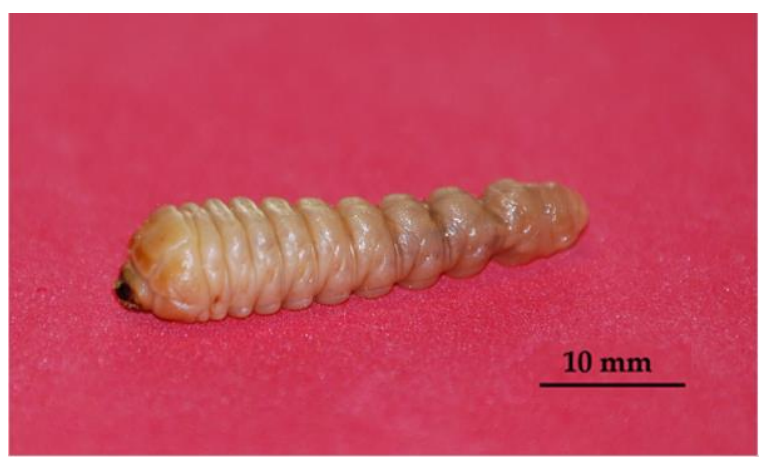

(b)

Figure 1. Stromatium unicolor (Olivier, 1795) (a) imago (F: female; M: male); (b) larvae.

The larvae selection was based on a biologic and evolutionary criterion: the largest larvae are the strongest and best adapted to their environment. Since their function at these stages is to pierce the wood and feed on it, the best-adapted larvae will have better wood cutting characteristics.

The low number of larvae used in the research was mainly due to three reasons: first, the difficulty of finding larvae in their last stage since they were extracted from holm oak firewood. As it does not come from a hatchery larva, their availability was limited. Second, taking into consideration the costs of testing the techniques and equipment used for a large number of tests would require a disproportionate economic contribution compared to the objective set. Moreover, finally, in other investigations to determine the geometric parameters of insects $[8,10,19,21,30,31,38,39]$, these were carried out with one to five larvae.

What has been done is a simplification since, if a larva has reached its last larval stages, the characteristics of the jaw are close-to-, or above-average. This is due to the act that if the jaw is not efficient in cutting, the insect could not have reached that stage because of the inability to feed.

We are aware of the limitations in this type of study using a single sample, due to the dimensional variability depending on the larval stage, but further biometric studies with a large number of individuals at different growth stages will advance the morphometrics of the head of xylophagous insects.

\subsection{Obtaining The Profile of The Jaw and Perpendicular Cut of The Musculature. Paraffin Inclusion}

First, a larva was selected and sectioned perpendicularly a few millimeters below the prothorax to obtaining the head, as shown in Figure $2 b$,d.

To obtain a precise and clean-cut section, the larvae were prepared using the paraffin embedding technique. First, they were dehydrated in an ethanol immersion; then, the samples were stained with a solution of ethanol and methylene blue. Before introducing the larvae into a paraffin bath, ethanol was extracted from the tissues with a xylene treatment. Xylene was used as an intermediate liquid 
between ethanol and paraffin since it is miscible in both. Once the paraffin solidified, it was removed from the mold and dissected by using a scalpel to expose the head of the larvae.

Then, cuts were made with a microtome until the desired plane was exposed, as shown in Figure 2.

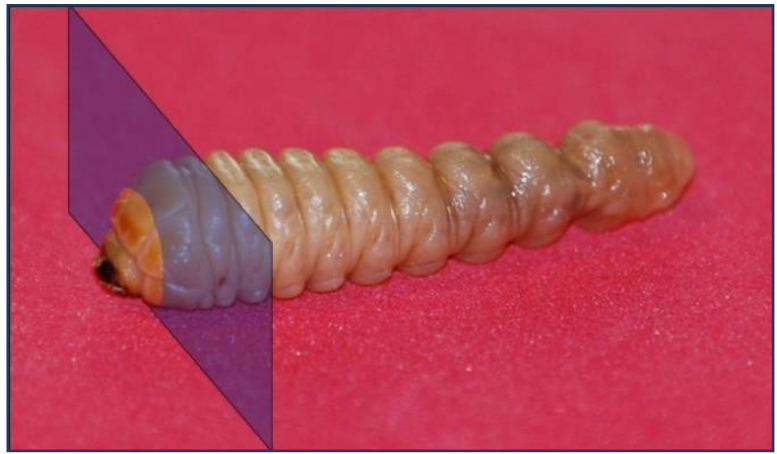

(a)

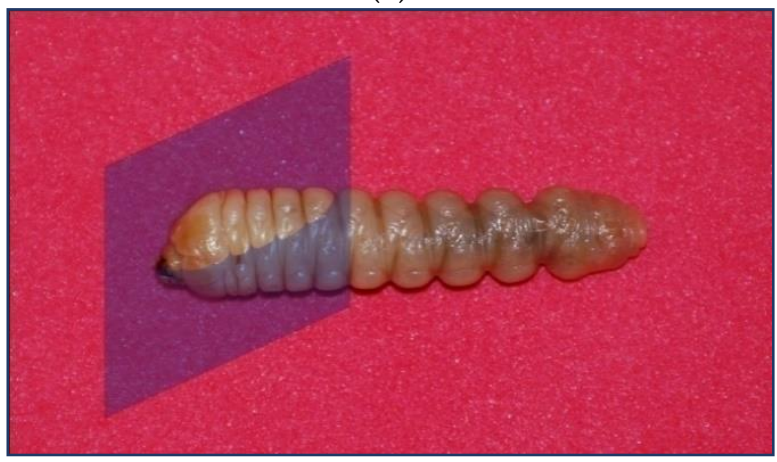

(c)

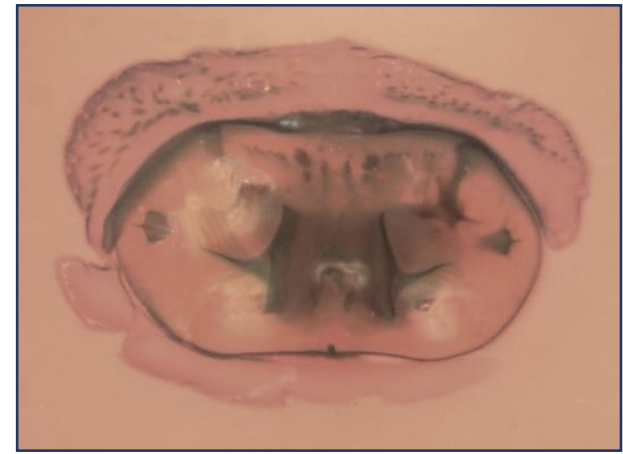

(b)

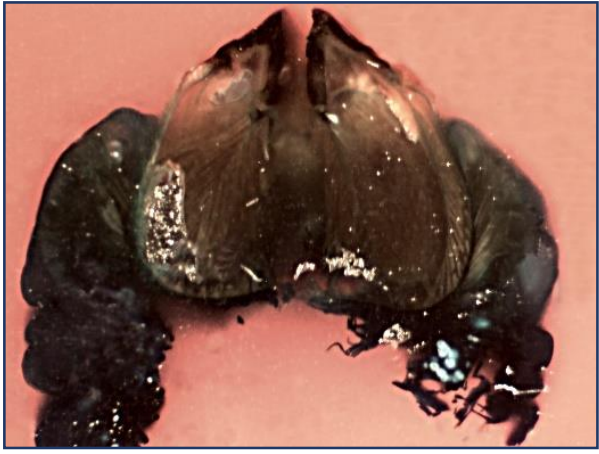

(d)

Figure 2. Larvae cutting analysis. (a) Cut perpendicular to the musculature. Plane where the cut was made; (b) resulting cut; (c) mandible profile. Plane where the cut was made; (d) resulting cut.

\subsection{Surface and Elemental Composition Analysis}

Composition analysis was performed using an FEI Quanta 200 (Thermo Fisher Scientific, Alcobendas, Spain) scanning electron microscope that operates with three vacuum modes (high vacuum, low vacuum and ambient mode), secondary and backscattered electron detectors for all vacuum modes and the integrated analysis system Oxford Instruments Analytical-Inca with two X-ray detectors, which can be simultaneously and alternatively used: dispersive energy spectroscopy (EDS) and dispersive wavelength spectroscopy (DWS). Before testing, the samples were washed with alcohol at different graduations $\left(70^{\circ}, 90^{\circ}, 96^{\circ}\right.$ and $\left.100^{\circ}\right)$. The cephalic capsule and prothorax assembly and an extruded mandible were observed. The surface characteristics and distributions of different chemical compositions were studied. After different areas were found, specific points were selected, where semiquantitative chemical microanalyses were performed.

\subsection{Measurement Methodology}

A stereomicroscope and an optical microscope with an image digitizing system were used to perform the geometric characterization of the mandibles. The images were subsequently analyzed using the Image-Pro Plus 4.0 software. With this software, after calibration with a specific standard, measurements of length, angles, etc. were obtained. The software manufacturer estimates that the error made in the measurement using this methodology is $3 \%$ of the measure. 


\section{Results and Discussion}

\subsection{Elemental Composition of The Mandibles}

The contrast difference in the strip next to the cutting edge in Figure 3 indicates that the mandible cut-area is reinforced with inclusions of elements of higher atomic weight than the remainder of the head and body. Studies of the cutting edges show a change in the composition of the jaw tissues [26].

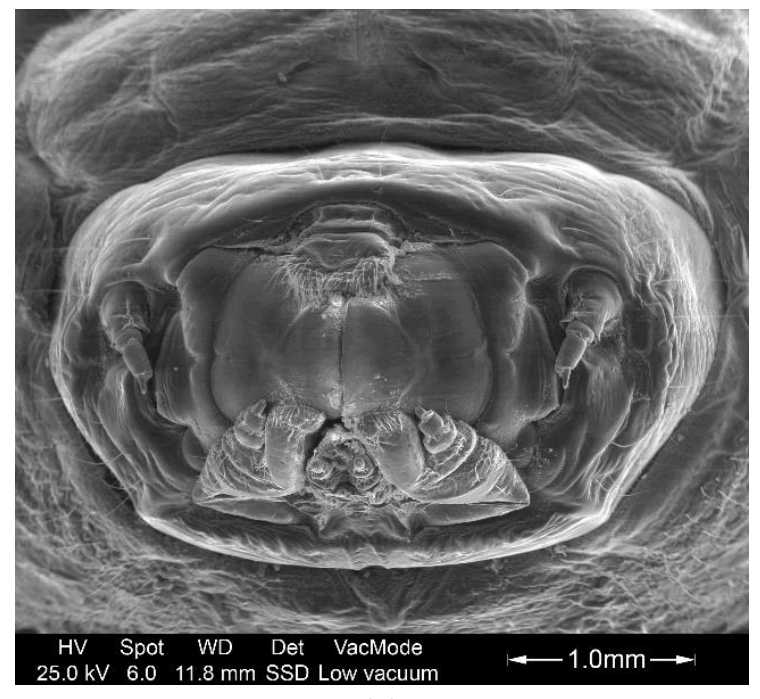

(a)

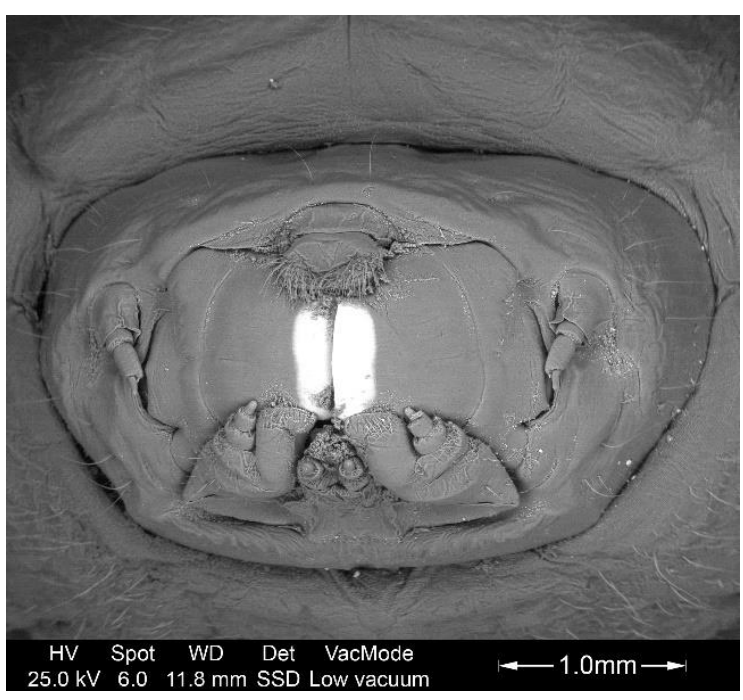

(b)

Figure 3. Image of the mandible obtained by (a) secondary electron detection and (b) backscattered electron detection. The contrast reveals differences in the chemical composition.

A semiquantitative chemical microanalysis using X-ray wavelength dispersion spectrometry showed that the tissues that experience the most significant stress during the bite are reinforced by elements such as zinc, manganese and chlorine (Figure 4). The analysis of the rake face showed meagre amounts of zinc and manganese and the absence of chlorine.

If the metabolism of these metallic elements by the insect can be limited or prevented using chelating substances [38], the tissues involved in cutting the wood are not reinforced by them, which affects the cutting and feeding capacity of the larva and protects the wood from attacks by xylophagous insects. 


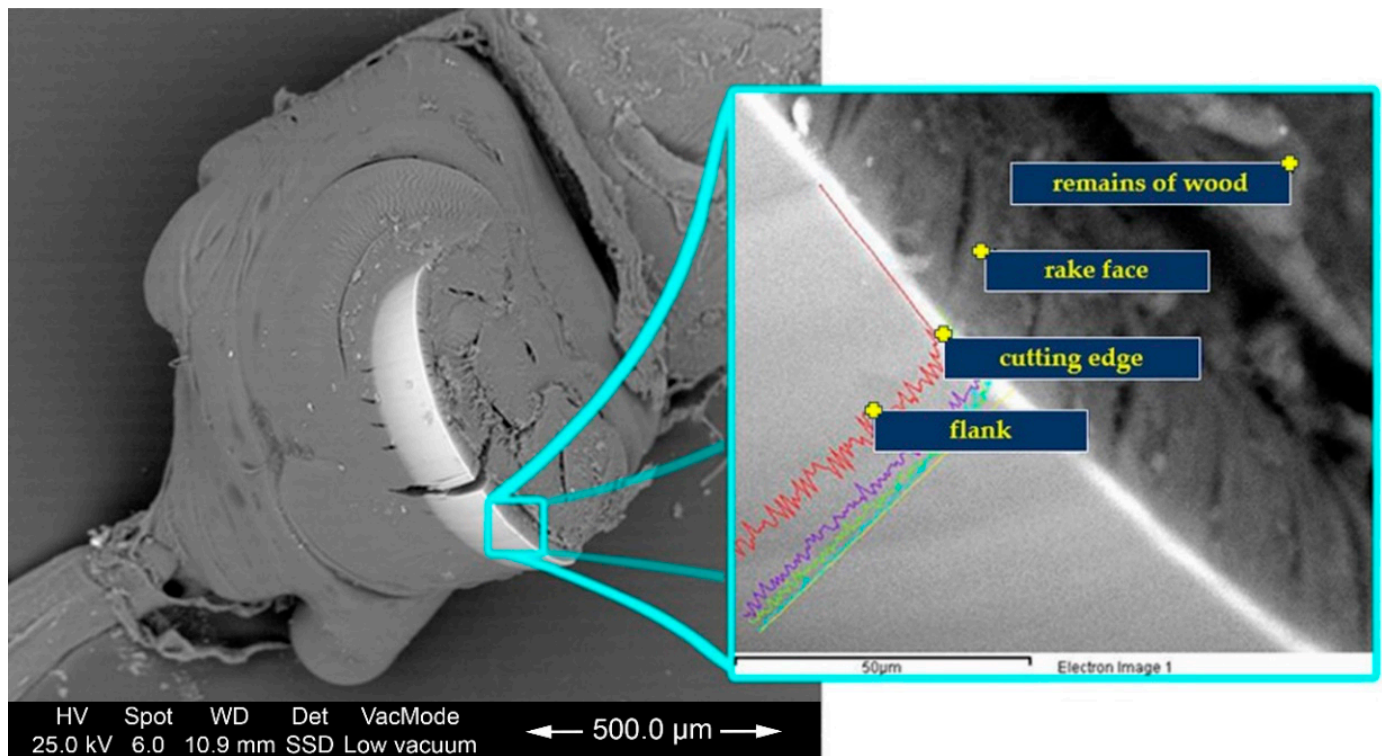

(a)

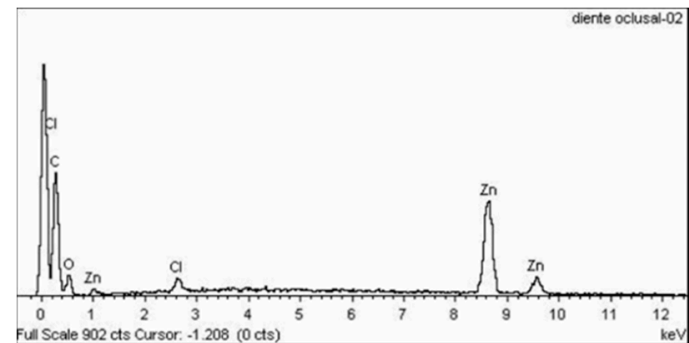

(b)

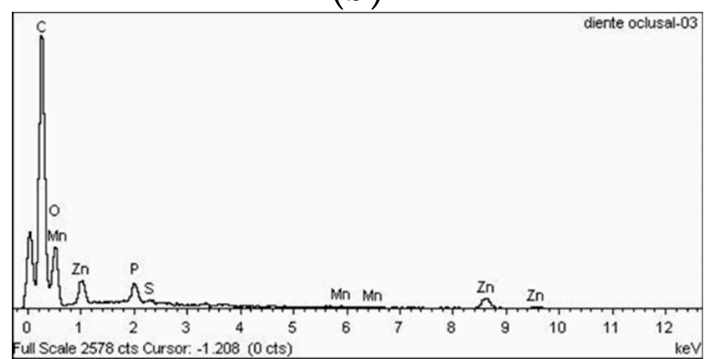

(d)

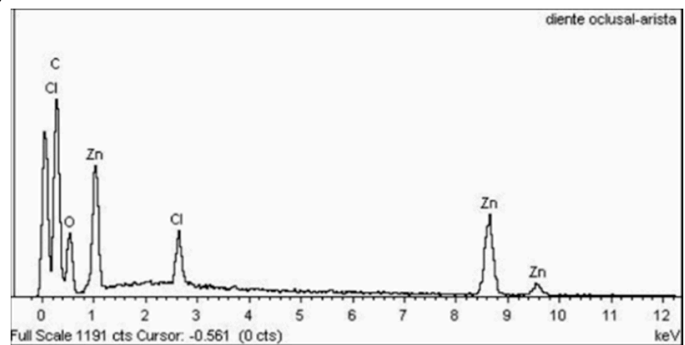

(c)

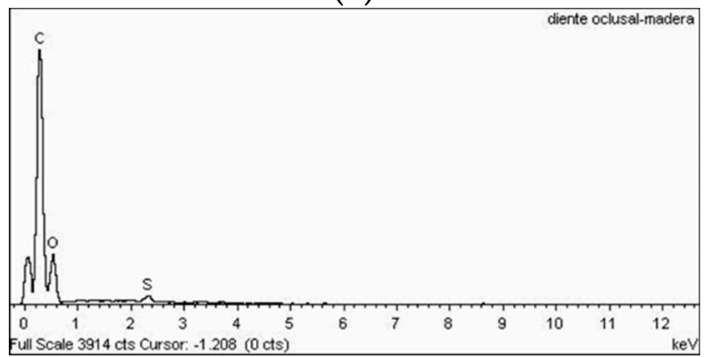

(e)

Figure 4. Semiquantitative chemical microanalysis points through X-ray wavelength dispersion spectrometry. (a) Location of the analysis points on the cut surfaces; (b) plots of the chemical microanalysis results of the flank of the jaw from the (c) cutting edge, (d) rake face of the jaw and (e) remains of wood in the jaw.

\subsection{Study of The Mandible Movement: Joints, Musculature and Footprint of The Bite}

Each tooth or jaw has two strongly chitinized hemispheres, which is similar to the head of a femur bone. These hemispheres are housed in separate cavities that are also strongly chitinized in the head (Figure 5). Thus, each tooth rotates through 2 points or joints that form an axis, and each jaw has a degree of freedom of movement in the cephalic capsule (rotation). The cephalic capsule has 3 degrees of freedom since it performs vertical, horizontal and extension movements. It appears similar to a robot with polar coordinate movements. 


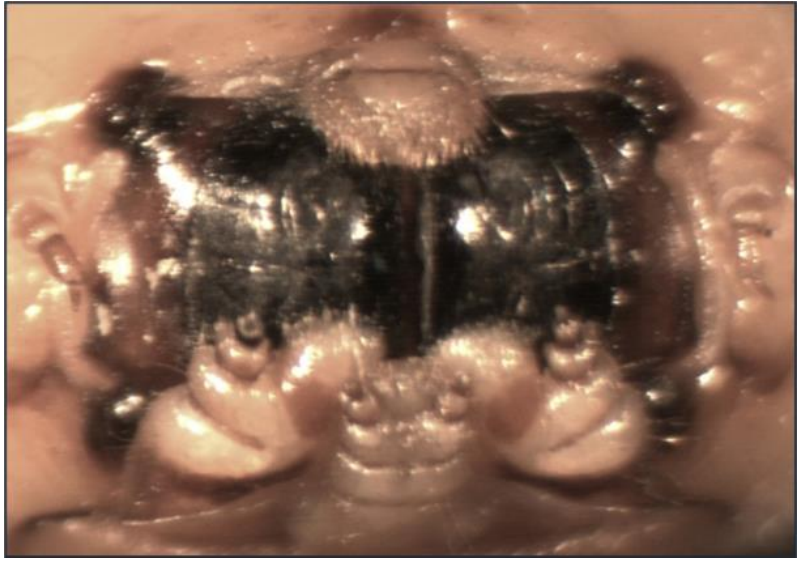

(a)

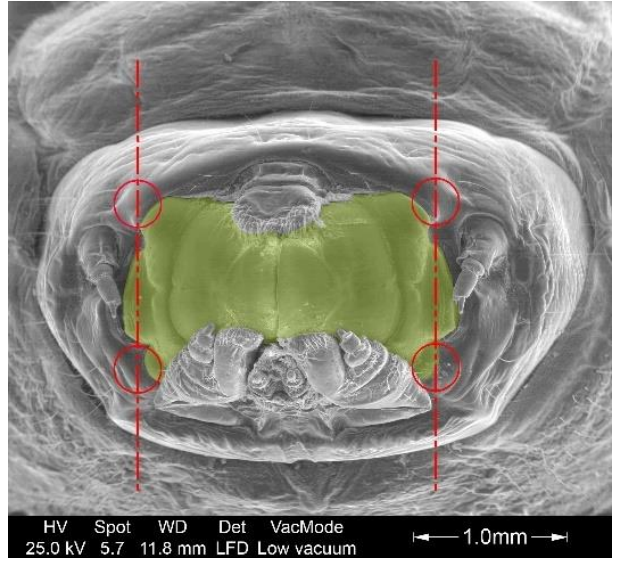

(b)

Figure 5. Mouthparts of the larva: (a) Optical microphotography of the mandible; (b) electron micrograph of the cephalic capsule. The mandibles are highlighted in green; the joints and axis of rotation are highlighted in red.

Inside the larva head are multiple muscles. Most of them are not crucial in the cutting movements and are therefore not the object of this study. We only focus on the main actuator muscles.

Three groups of muscles are mainly involved in the cutting movement: The adductors are responsible for the closing movement of the jaw and therefore are the most responsible for the cutting action. The abductors are accountable for the mandibular opening, and the extension muscles of the cephalic capsule cause its movement outward and into the prothorax and are responsible for bringing it closer to the wood and supporting its perpendicular reaction force. As shown in Figure 6, the adductor muscles have a much higher volume than the other muscles since they provide the main cutting power.

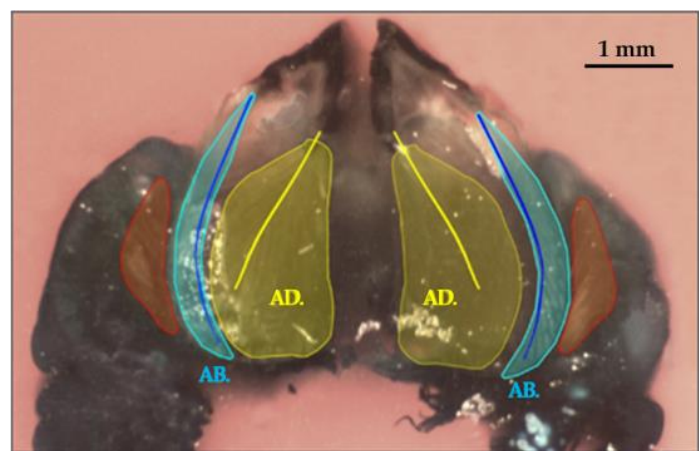

(a)

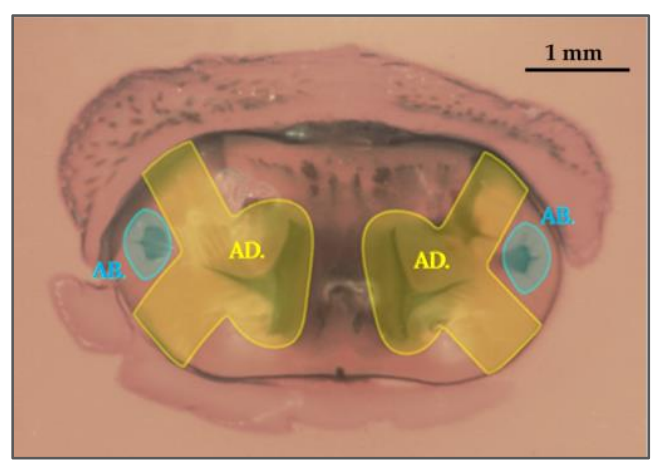

(b)

Figure 6. Optical micrographs: (a) longitudinal and (b) cross-section of the cephalic capsule and prothorax. The adductor muscles (AD) are highlighted in yellow, the abductor muscles (AB) are highlighted in light blue, and the exit and entrance muscles of the cephalic capsule are highlighted in orange.

The difference in muscle power is observed in the size of the tendons that transmit the effort to the jaw. Figure 7 shows the abductor tendon highlighted in green on the left and the adductor tendon on the right, which is several times larger than the tendon on the left. 


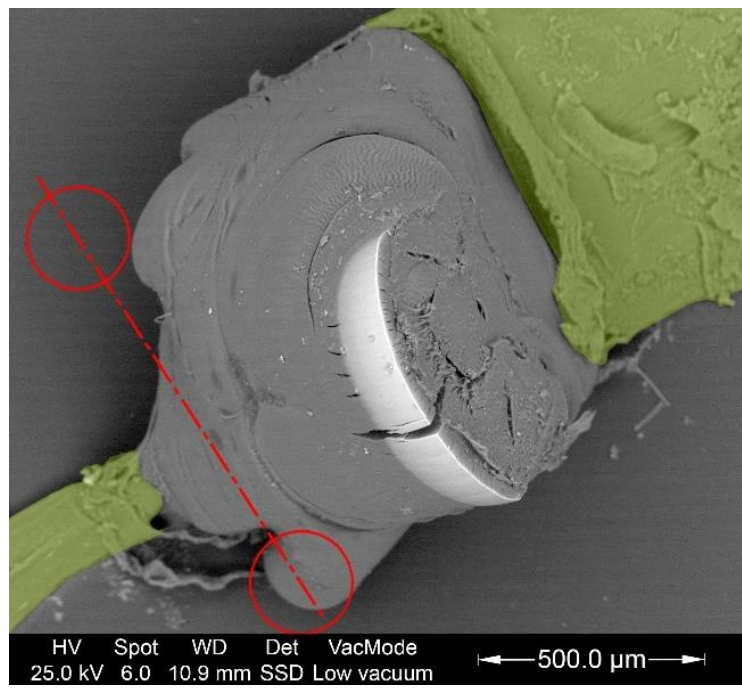

Figure 7. Electron micrograph of the right mandible. The tendons are highlighted in green and the joints and axis of rotation are highlighted in red.

To pierce the wood, the larvae use two main opening and closing movements. First, by contracting the muscle bundles in the prothorax, the cephalic capsule leaves the prothorax (similar to the head of a turtle emerging from its shell) to bring the jaw closer to the wood. While performing this movement, the larva opens the jaw using the abductor muscles. Once the open mouth makes contact with the wood, it exerts pressure and closes the jaws with the adductor muscles to cut.

\subsection{Tool Footprint (Mandible)}

As shown in Figure 8, the jaw cut is not clean. It produces tears in the wood fibers and breaks at different depths due to bending and shear stresses. The estimated moisture content of the holm oak wood in which the larva was feeding was approximately $16 \%$.

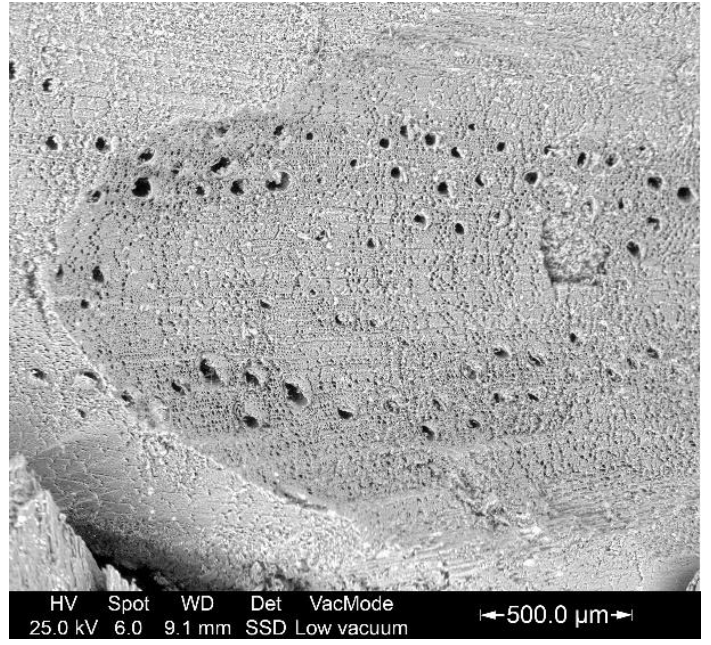

(a)

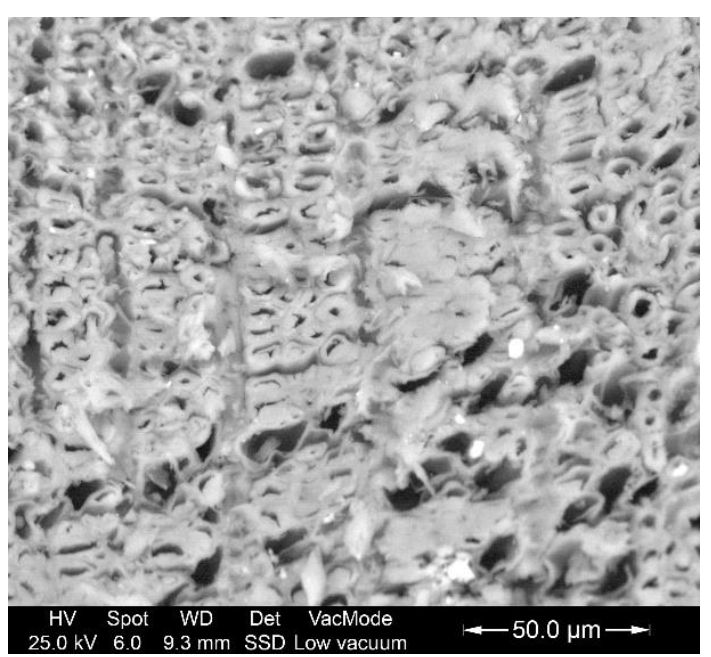

(b)

Figure 8. Electron micrographs of the cut footprint made by the insect in a cross section of holm oak wood. Torn cells of polygonal sections are observed. (a) Whole footprint; (b) detail of the latewood zone in the annual ring.

Figure 9a shows that the footprint begins to smoothly deepen, takes a semicircular path, and ends in an almost vertical wall, which leaves a type of burr. Since this footprint is not symmetrical, it is 
conceivable that the cut is made by one jaw at a time. To more quickly visualize the characteristics, Figure $9 \mathrm{~b}$ shows a larva bite simulation.

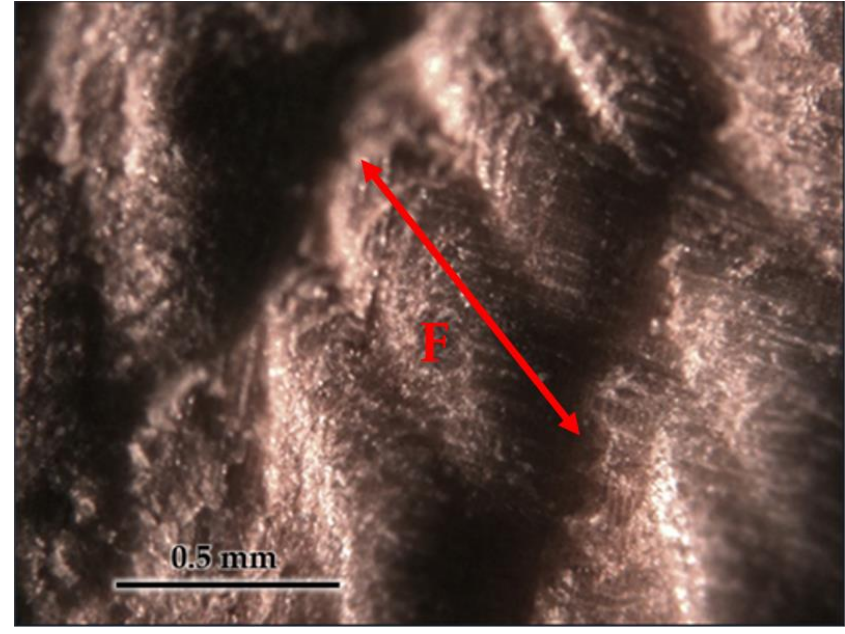

(a)

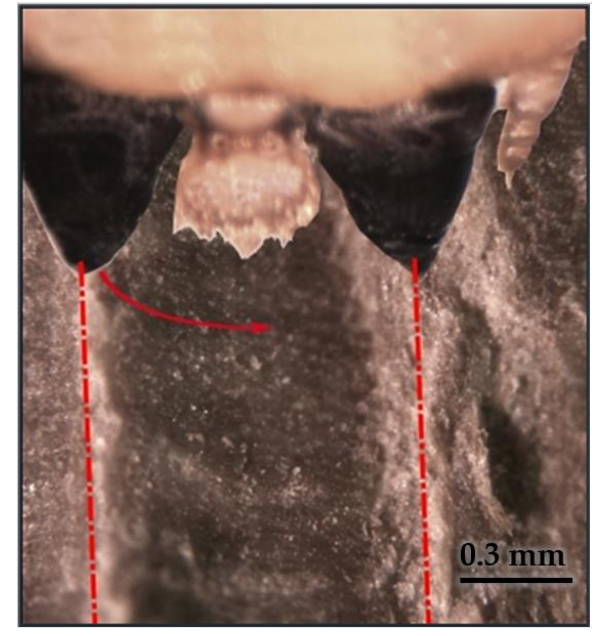

(b)

Figure 9. Optical microphotography of the cut footprint (a) with shadow play (bite length $\mathrm{F}=800 \mu \mathrm{m}$ ) and (b) a photographic montage of the larva cutting.

From the study of the joints, muscles, tendons and footprint of the mandibles, it can be deduced that the larva primary cutting mechanism consists of using one of the jaws as an anchor or stop. Simultaneously, the other performs chip removal, which describes a semicircular movement until the jaws touch each other. This mechanism can be observed in the imprint of the mandibular tool left on the wood. We say that it is its primary cutting mechanism because since it is a living being, it can change its modus operandi depending on its needs, the shape of the wood, the hardness of the wood, etc.

\subsection{Cut Type}

Each jaw rotates through 2 points or joints that form an axis. The cutting edge and articular axis form a plane, and the axes of the two teeth are parallel, as shown in Figure 10. Therefore, the cutting edge of the mandible is perpendicular to the direction of the cut. Thus, the cutting movement of the insect is orthogonal.

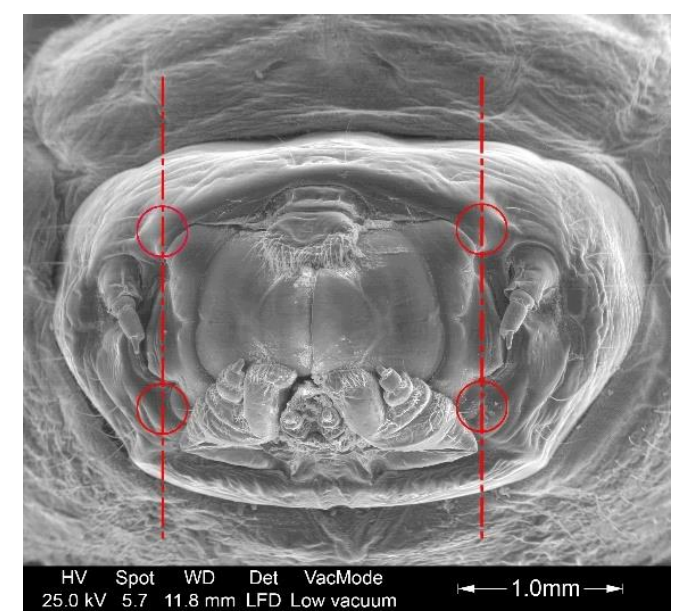

Figure 10. Mandibular joints and axes of rotation locations. 


\subsection{Geometric Characterization of The Mandibles}

\subsubsection{Geometric Parameters}

The wedge angle of the mandible near its plane of symmetry is $\beta=77.3^{\circ}$. The angle between the rake face and the segment that joins the cutting edge with the muscular insertion of the mandible is $\delta=9.6^{\circ}$. The position and dimensions of the jaws were characterized from segments $\mathrm{A}, \mathrm{B}$ and $\mathrm{C}$ and $\mathrm{at}$ angles $a$ and b, as shown in Figure 11.

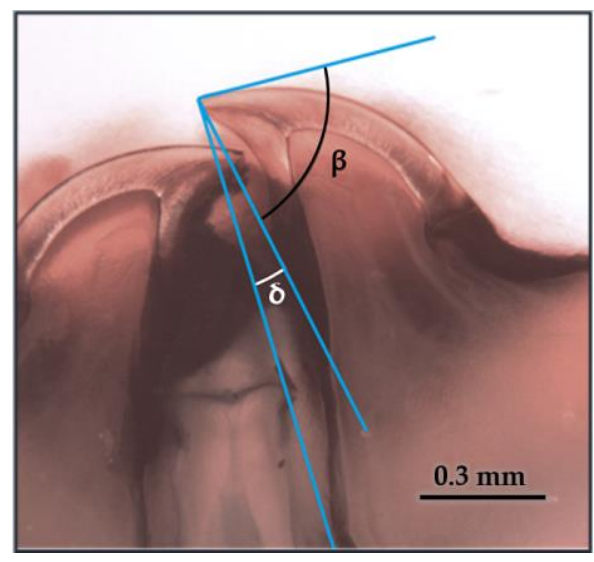

(a)

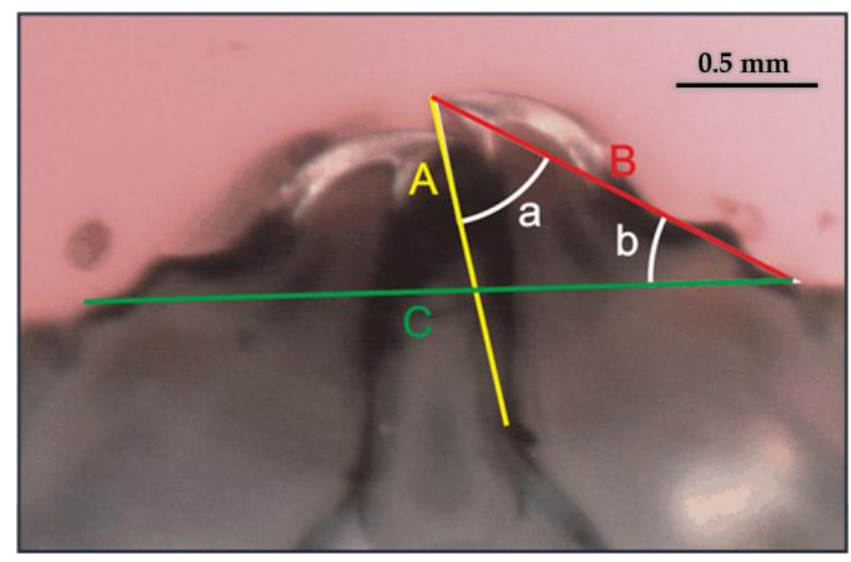

(b)

Figure 11. Distances and angles: (a) Jaw wedge angle $\beta=77.3^{\circ}$ and the angle between segment A and the rake face $\mathrm{c}=9.6^{\circ} ;(\mathbf{b}) \mathrm{A}=1249 \mu \mathrm{m}$ is the distance between cutting edge and insertion of the adductor, $\mathrm{B}=1496 \mu \mathrm{m}$ is the distance between the cutting edge and the articulation axis radius of rotation of the jaw, $\mathrm{C}=2539 \mu \mathrm{m}$ is the joint distance, $\mathrm{a}=44.8^{\circ}$ is the angle between segments $\mathrm{A}$ and $\mathrm{B}$ and $b=30.9^{\circ}$ is the declination angle between segments $B$ and $C$.

The bite length $(\mathrm{F}=800 \mu \mathrm{m})$ was obtained by measuring the length of the cutting footprint in the wood (Figure 9a).

\subsubsection{Radius and Arches}

The radii that describe the flank face, cutting edge and radius of the edge were identified and measured, as shown in Figure 12.

The arc of the cutting edge is offset from the axis of symmetry of the jaw (Figure 12c). The maximum depth of the cut of the insect $(\mathrm{D}=120 \mu \mathrm{m})$ was deduced from the distance between the line tangent to the center of the arc of the cutting edge and the line formed by its ends as shown in Figure 12d. 


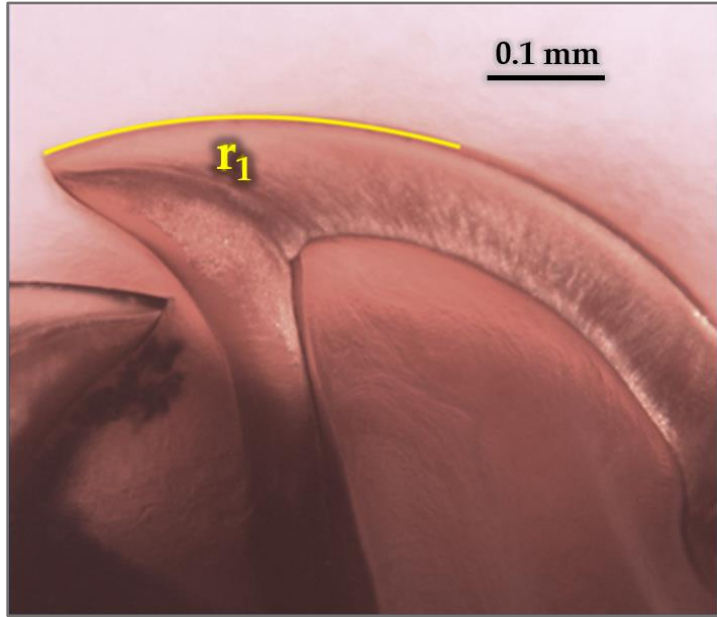

(a)

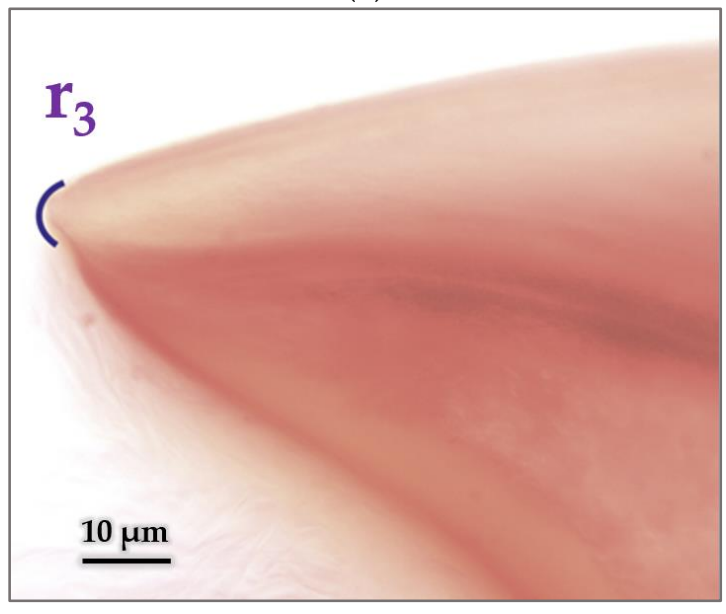

(c)

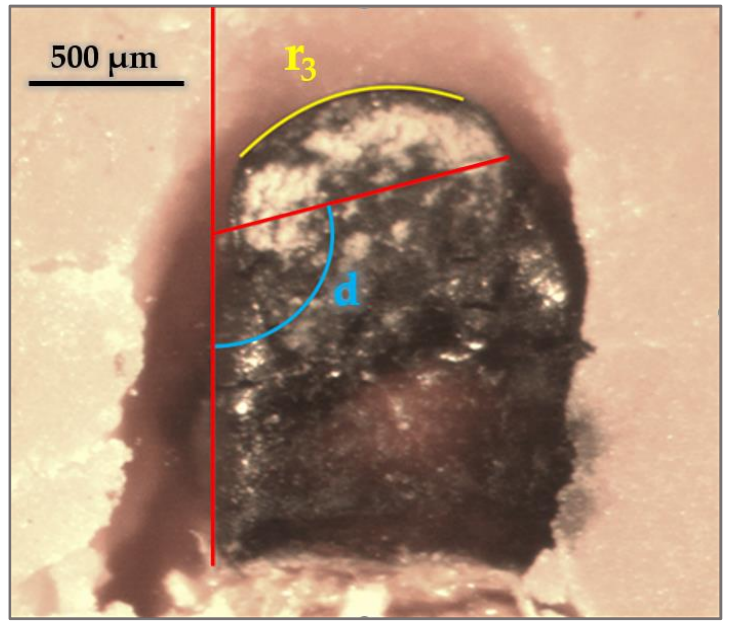

(b)

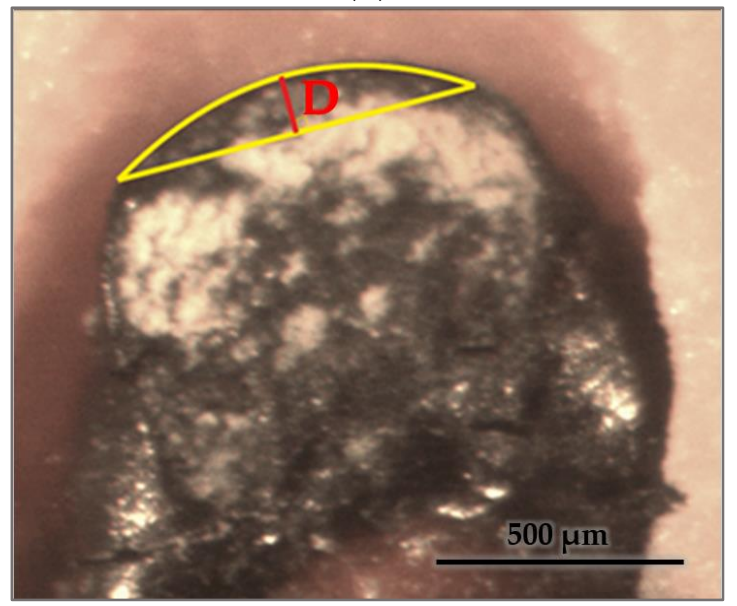

(d)

Figure 12. The radius and arches of the mandibles: (a) Radius of curvature of the flank r1 = $566 \mu \mathrm{m}$; (b) radius of the arc of the cutting edge $\mathrm{r} 2=574 \mu \mathrm{m}$; (c) edge radius $\mathrm{r} 3=3 \mu \mathrm{m}$; (d) angle of the tangent to the cutting arc with the longitudinal axis of the jaw $\mathrm{d}=106.5^{\circ} ;(\mathrm{d})$ maximum cut depth of the insect bite $\mathrm{D}=120 \mu \mathrm{m}$.

\subsubsection{Cutting Edge}

The cutting edge of this species is smooth without protuberances or defined shapes, as shown in Figure 13. In other species, the cutting edge has periodic forms; for example, Schmidt, H. and Parameswaran, N. commented that the cutting edge of the jaw of Hylotrupes bajulus L. described a zigzag of approximately $120^{\circ}$ [39]. This particular insect feeds on coniferous wood with densities on the order of $450-600 \mathrm{~kg} / \mathrm{m}^{3}$. 


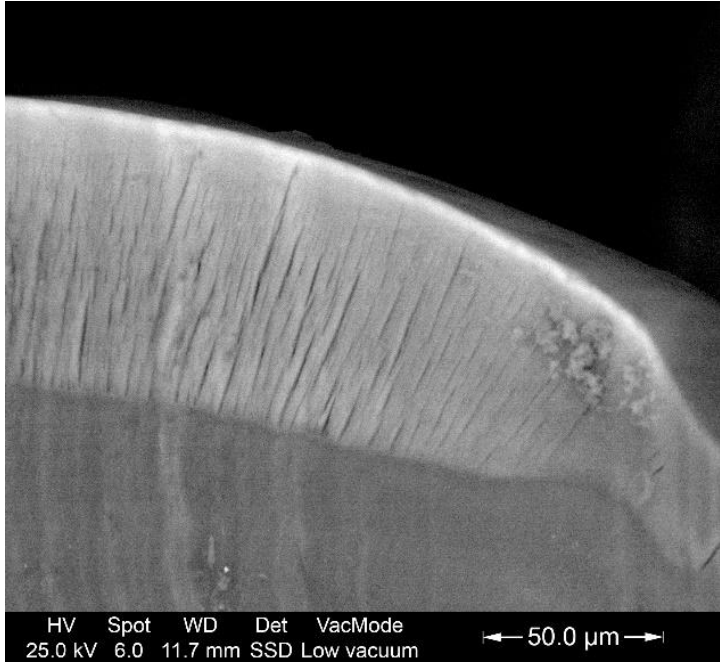

(a)

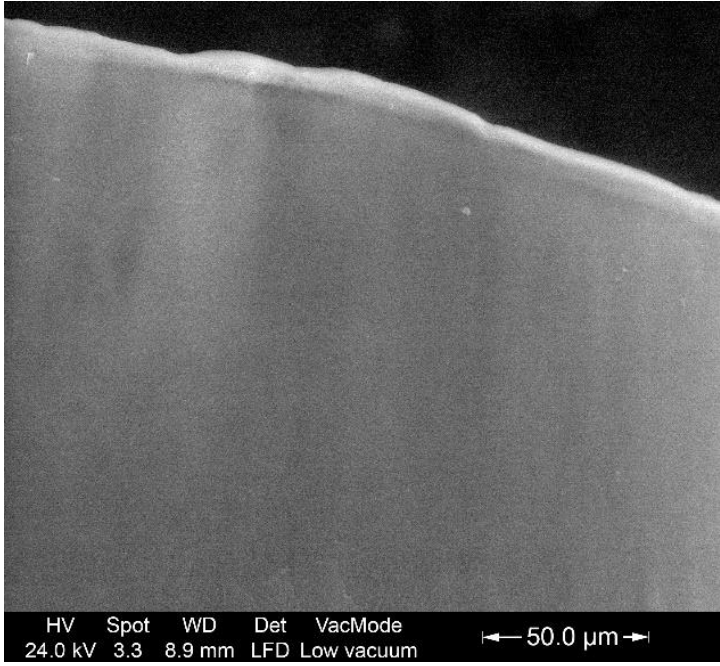

(b)

Figure 13. (a) Smooth cut edge detail; (b) detail of the rake face without texture. The cracks are due to drying of the specimen.

\section{Conclusions}

The material, morphology, geometry and mechanical properties of the mouthparts of longhorn beetle (Stromatium unicolor) in its larva stage were analyzed in this study, which will increase the knowledge of the cutting mechanics of this insect.

The primary cutting mechanism of the larva consists of using one of the jaws as an anchor or stop. Simultaneously, the other jaw performs chip removal, which describes a semicircular movement until they come together. The analysis of the footprint in the wood concludes that the cut produced by the larva's jaw is not clean and has a rough surface finish, since it produces tears in the fibers and breaks at different depths due to bending and shear stresses. The tissues of the insect jaw that are directly involved in cutting are subjected to higher stresses, including wear stress, than the other tissues. Therefore, they are reinforced with higher atomic weight elements such as zinc and manganese. Meanwhile, the inner tissues that are not directly involved in shear stresses are not reinforced.

From the analysis of the musculature and joints of the larva, of the three principal muscle bundles that intervene in the cutting movement, the adductors are responsible for the closing movement of the jaw and therefore are the main responsible muscle bundle for the action of the cut. To pierce the wood, the larva uses two main movements.

The joint analysis and geometric characterization of the mandibles showed that the cutting movement of the insect is orthogonal and that the cutting edge of the larva's jaw is smooth.

The most significant mandibles geometric parameters were also found.

The results of this study serve as a reference in the investigation of this specific species. Possible lines of research to follow in the future include studies of the non-stick surface characteristics of the jaws, molecular compounds that form the reinforcing elements in the chitin matrix, inhibitors of metal absorption and metabolism as wood preservatives and joint research of different species of xylophages that attack different species of wood.

Author Contributions: Conceptualization, R.D.M.; data curation, R.D.M.; formal analysis, R.D.M.; funding acquisition, R.D.M., J.-A.B. and L.A.; Investigation, R.D.M.; methodology, R.D.M.; Project administration, R.D.M.; resources, R.D.M.; supervision, R.D.M.; writing—original draft, R.D.M., J.-A.B., L.A. and L.-A.B.; writing一review \& editing, R.D.M., J.-A.B., L.A. and L.-A.B. All authors have read and agreed to the published version of the manuscript.

Funding: This research received no external funding.

Acknowledgments: We thank Unidad Docente de Patología forestal y Conservación de madera de ETSI de Montes de La Universidad Politécnica de Madrid, Spain; Unidad Docente de Industrias de los Productos Forestales de 
EUIT Forestal de la Universidad Politécnica de Madrid, Spain; Unidad Docente de Zoología y Enfermedades y Plagas de la EUIT Forestal de la Universidad Politécnica de Madrid, Spain; Eduard Vives for his advice and Sara Garrido Espinosa for the photo retouching and digital montage.

Conflicts of Interest: The authors declare no conflicts of interest.

\section{References}

1. Thompson, D.W. On Growth and Form; Cambridge University Press: Cambridge, UK, 1942.

2. Hwang, J.; Jeong, Y.; Park, J.M.; Lee, K.H.; Hong, J.W.; Choi, J. Biomimetics: Forecasting the future of science, engineering, and medicine. Int. J. Nanomed. 2015, 10, 5701. [CrossRef]

3. Nachtigall, W.; Wisser, A. Bionics by Examples. 250 Scenarios from Classical to Modern Times; Springer: Berlin/Heidelberg, Germany, 2014.

4. Tong, J.; Moayad, B.Z.; Ma, Y.H.; Sun, J.Y.; Chen, D.H.; Jia, H.L.; Ren, L.Q. Effects of biomimetic surface designs on furrow opener performance. J. Bionic Eng. 2009, 6, 280-289. [CrossRef]

5. Betz, O.; Wegst, U.; Weide, D.; Heethoff, M.; Helfen, L.; LEE, W.K.; Cloetens, P. Imaging applications of synchrotron $\mathrm{X}$-ray phase-contrast microtomography in biological morphology and biomaterials science. I. General aspects of the technique and its advantages in the analysis of millimetre-sized arthropod structure. J. Microsc. 2007, 227, 51-71. [CrossRef]

6. Michels, J.; Gorb, S.N. Detailed three-dimensional visualisation of resilin in the exoskeleton of arthropods using confocal laser scanning microscopy. J. Microsc. 2012, 245, 1-16. [CrossRef]

7. Liu, C.; Liu, J.; Xu, L.; Xiang, W. Recent achievements in bionic implementations of insect structure and functions. Kybernetes 2014, 43, 307-324. [CrossRef]

8. Sun, J.; Ling, M.; Wu, W.; Bhushan, B.; Tong, J. The hydraulic mechanism of the unfolding of hind wings in Dorcus titanus platymelus (order: Coleoptera). Int. J. Mol. Sci. 2014, 15, 6009. [CrossRef]

9. William, E.G.; Paul, Y.O.; Geoffrey, B. Flying insect inspired vision for autonomous aerial robot manoeuvres in near-earth environments. In Proceedings of the IEEE International Conference on Robotics \& Automation, New Orleans, LA, USA, 26 April-1 May 2004.

10. Du, J.; Hao, P. Investigation on microstructure of beetle elytra and energy absorption properties of bio-inspired honeycomb thin-walled structure under axial dynamic crushing. Nanomaterials 2018, 8, 667. [CrossRef]

11. Chen, B.; Peng, X.H.; Fan, J.H. Microstructure of natural biocomposites and research of biomimetic composites. Acta Mater. Comp. Sin. 2000, 17, 59-62.

12. Schleicher, S.; Kontominas, G.; Makker, T.; Tatli, I.; Yavaribajestani, Y. Studio One: A New Teaching Model for Exploring Bio-Inspired Design and Fabrication. Biomimetics 2019, 4, 34. [CrossRef]

13. Hörnschemeyer, T.; Bond, J.; Young, P.G. Analysis of the functional morphology of mouthparts of the beetle Priacma serrata, and a discussion of possible food sources. J. Insect Sci. 2013, 13, 126. [CrossRef]

14. Ball, G.E.; Acorn, J.H.; Shpeley, D. Mandibles and labrum-epipharynx of tiger beetles: Basic structure and evolution (Coleoptera, Carabidae, Cicindelitae). ZooKeys 2011, 147, 39-83. [CrossRef]

15. Angelini, D.R.; Smith, F.W.; Aspiras, A.C.; Kikuchi, M.; Jockusch, E.L. Patterning of the adult mandibulate mouthparts in the red flour beetle, Tribolium castaneum. Genetics 2012, 190, 639-654. [CrossRef] [PubMed]

16. Zhang, K.; Ji, B.Z.; Liu, S.W.; Qing, Z.H. Primary Research of Bionic Design on Tools with Mouthpart of Larvae Long Horned Beetles. Adv. Mater. Res. 2011, 142, 139-142. [CrossRef]

17. Meyers, M.A.; Lin, A.Y.M.; Lin, Y.S.; Olevsky, E.A.; Georgalis, S. The cutting edge: Sharp biological materials. JOM 2008, 60, 19-24. [CrossRef]

18. Zhang, K.; Zhong, B.; Lui, S.W.; Hua, Z. Research of Bionic Design on Tools with Chewing Mouthparts of Insects. Adv. Mater. Res. 2012, 426, 270-274. [CrossRef]

19. Zhao, J.; Guo, M.; Lu, Y.; Huang, D.; Zhuang, J. Design of bionic locust mouthparts stubble cutting device. Int. J. Agric. Biol. Eng. 2020, 13, 20-28. [CrossRef]

20. Gao, H.; Li, Y.Z.; Tong, J.; Sun, J.Y. Microstructure and nanoindentation properties of mouthparts of Oriental Mole Cricket. Trans. Chin. Soc. Agric. Mach. 2011, 42, 224-227.

21. Tong, J.; Xu, S.; Chen, D.; Li, M. Design of a bionic blade for vegetable chopper. J. Bionic. Eng. 2017, 14, 163-171. [CrossRef]

22. Hillerton, J.E.; Reynolds, S.E.; Vincent, J.F.V. On the indentation hardness of insect cuticle. J. Exp. Biol. 1982, $96,45-52$. 
23. Cribb, B.W.; Stewart, A.; Huang, H.; Truss, R.; Noller, B.; Rasch, R.; Zalucki, M.P. Insect mandibles-comparative mechanical properties and links with metal incorporation. Naturwissenschaften 2008, 95, 17-23. [CrossRef]

24. Edwards, A.J.; Fawke, J.D.; McClements, J.G.; Smith, S.A.; Wyeth, P. Correlation of zinc distribution and enhanced hardness in the mandibular cuticle of the leaf-cutting and Atta sexdens rubropilosa. Cell Biol. Int. 1993, 17, 697-698. [CrossRef]

25. Fawke, J.D.; McClements, J.G.; Wyeth, P. Cuticularmetals: Quantification and mapping by complimentary techniques. Cell Biol. Int. 1997, 21, 675-678. [CrossRef] [PubMed]

26. Hillerton, J.E.; Vincent, J.F.V. The specific locations of zinc in insect mandibles. J. Exp. Biol. 1982, 101, $333-336$.

27. Hillerton, J.E.; Robertson, B.; Vincent, J.F.V. The presence of zinc of manganese as the predominant metal in the mandibles of adult, stored-product beetles. J. Stored Prod. Res. 1984, 20, 133-137. [CrossRef]

28. Schofield, R.; Lefevre, H. High concentrations of zinc in the fangs and manganese in the teeth of spiders. J. Exp. Biol. 1989, 144, 577-581.

29. Vincent, J.F.V.; Wegst, U.G.K. Design and mechanical properties of insect cuticle. Arthropod Struct. Dev. 2004, 33, 187-199. [CrossRef] [PubMed]

30. Li, L.; Guo, C.; Xu, S.; Li, X.; Han, C. Morphology and nanoindentation properties of mouthparts in Cyrtotrachelus longimanus (Coleoptera: Curculionidae). Microsc. Res. Tech. 2017, 80, 704-711. [CrossRef]

31. Büsse, S.; Gorb, S.N. Material composition of the mouthpart cuticle in a damselfly larva (Insecta: Odonata) and its biomechanical significance. R. Soc. Open Sci. 2018, 5, 172117. [CrossRef]

32. Casado-Sanz, M.M.; Silva-Castro, I.; Ponce-Herrero, L.; Martín-Ramos, P.; Martín-Gil, J.; Acuña-Rello, L. White-rot fungi control on Populus spp. Wood by pressure treatments with silver nanoparticles, chitosan oligomers and propolis. Forests 2019, 10, 885. [CrossRef]

33. Kaur, P.; Thakur, R.; Choudhary, A. An in vitro study of the antifungal activity of silver/chitosan nanoformulations against important seed borne pathogens. Int. J. Sci. Technol. Res. 2012, 1, 83-86.

34. Silva-Castro, I.; Martín-García, J.; Diez, J.J.; Flores-Pacheco, J.A.; Martín-Gil, J.; Martín-Ramos, P. Potential control of forest diseases by solutions of chitosan oligomers, propolis and nanosilver. Eur. J. Plant Pathol. 2017, 150, 401-411. [CrossRef]

35. Kartal, S.N.; Green, F.; Clausen, C.A. Do the unique properties of nano-metals affect leachability or efficacy against fungi and termites? Int. Biodeterior. Biodegrad. 2009, 63, 490-495. [CrossRef]

36. Matsunaga, H.; Kiguchi, M.; Evans, P.D. Microdistribution of copper-carbonate and iron oxide nanoparticles in treated wood. J. Nanopart. Res. 2008, 11, 1087-1098. [CrossRef]

37. Marzbani, P.; Mohammadnia-afrouzi, Y. Investigation on leaching and decay resistance of wood treated with nano-titanium dioxide. Adv. Environ. Biol. 2014, 8, 974-979.

38. Broomell, C.C.; Mattoni, M.A.; Zok, F.W.; Waite, J.H. Critical role of zinc in hardening of Nereis jaws. J. Exp. Biol. 2006, 209, 3219-3225. [CrossRef] [PubMed]

39. Schmidt, H.; Parameswaran, N. Mandibeln des Hausbockkäfers (Hylotrupes bajulus L.) und Fraßstruktur des Holzes im Rasterelektronenmikroskop. Zeitschrift für Angewandte Entomologie 1977, 84, 407-412. [CrossRef]

(C) 2020 by the authors. Licensee MDPI, Basel, Switzerland. This article is an open access article distributed under the terms and conditions of the Creative Commons Attribution (CC BY) license (http://creativecommons.org/licenses/by/4.0/). 